\title{
Biosimilars in dermatology: The wind of change (Review)
}

\author{
MARIA MAGDALENA CONSTANTIN ${ }^{1,2}$, CRISTINA MIHAELA CRISTEA ${ }^{3}$, TATIANA TARANU ${ }^{4}$, \\ STEFANA BUCUR $^{1}$, TRAIAN CONSTANTIN ${ }^{5}$, ALINA DINU ${ }^{1}$, MARIANA JINGA $^{6}$ and IULIANA ELENA NITA ${ }^{1}$ \\ ${ }^{1}$ The Second Department of Dermatology, Colentina Clinical Hospital, 020125 Bucharest; ${ }^{2}$ Department of Dermatology, \\ 'Carol Davila' University of Medicine and Pharmacy, 050474 Bucharest; ${ }^{3}$ Petroleum and Gas University of Ploiesti, \\ Medical Office, 100680 Ploiesti; ${ }^{4}$ Department of Oral Dermatology, 'Gr. T. Popa’ University of Medicine and Pharmacy, \\ 700115 Iasi; ${ }^{5}$ Department of Urology, 'Carol Davila' University of Medicine and Pharmacy, 050474 Bucharest; \\ ${ }^{6}$ Department of Gastroenterology, 'Carol Davila' Central Military Emergency University Hospital, 010825 Bucharest, Romania
}

Received September 11, 2018; Accepted January 14, 2019

DOI: 10.3892/etm.2019.7505

\begin{abstract}
Biosimilars are new drugs, highly similar copies of biological medicines, equally effective and safe but at lower prices. The aim of this brief review is to provide the current status of biosimilars approved in the European Union for dermatological use. We used PubMed for literature search up to June 2018. The keyword 'biosimilars' was searched and 1,691 items were found. From the 1,691 studies, we included 34 articles in our review. Biologics, biosimilars and generics are different types of drugs. Biosimilars are complex molecules produced by a difficult manufacturing process, and changes in product quality may affect its safety and efficacy. Now, there are 9 biosimilar medicines approved by European Medicines Agency (EMA) for plaque psoriasis and hidradenitis suppurativa: Amgevita, Solymbic, Cyltezo, Imraldi, Benepali, Erelzi, Flixabi, Inflectra and Remsima, and the number is increasing. In 2005, EMA issued the first guidelines for approval of biosimilars. Next-generation biologics, called 'biobetters', have the same target or mechanism of action as previously approved biologics, but they have structural changes and an improved formulation. The debate over the future of biosimilars is far from being finished. The explosive development of biological therapy and the emergence of biosimilars represent a significant success in the effort to provide advanced healthcare to patients all over the world.
\end{abstract}

Correspondence to: Dr Iuliana Elena Nita, The Second Department of Dermatology, Colentina Clinical Hospital, 19-21 Stefan cel Mare Street, 020125 Bucharest, Romania

E-mail: nitaiulianaelena@yahoo.com

Key words: psoriasis, biological therapy, biosimilars, biobetters, generics

\section{Contents}

1. Introduction

2. Literature search

3. Biologics, biosimilars and generics

4. Manufacturing biosimilars

5. Biosimilar medicines used in dermatology approved by EMA

6. The future pathway ahead

7. Conclusions

\section{Introduction}

Biosimilars are new drugs, highly similar copies of complex biological medicines, equally effective and safe but at lower prices (1). Biosimilars are made by or derived from a biological source. They entered the market due to the patents for the biologics had expired. Biosimilars increase the competition among manufacturers of biologic therapies and improve savings in healthcare systems $(2,3)$.

A biologic drug is 'a medicine whose active substance is made by a living organism' (4). They may be small molecule mimetics, recombinant proteins, monoclonal antibodies (mAbs) or fusion proteins (5).

The objective of this brief review is to provide the status of biosimilars approved for dermatological use.

\section{Literature search}

Our electronic search included the database PubMed, we used it for literature search up to June 2018. The keyword 'biosimilars' was searched and 1,691 items were found. From the 1,691 studies, we included 34 articles in our review.

We reviewed the most relevant and updated articles and eliminated the studies we considered to be irrelevant for the design of our study based on the year of publication, title, abstract, publisher's prestige, credibility and prestige of the journal, validity and importance of data presented and language.

We included studies with abstracts and/or titles focusing on the biosimilars of infliximab, etanercept or adalimumab, 
published in the last 10 years in prestigious journals. We excluded studies published in a language other than English, studies without valid data and scientifically unimportant results.

Additional searches were made on the internet, especially on the official websites of The European Medicines Agency (EMA) and US Food and Drug Administration. All publications included were in English. Four reviewers screened the studies identified by the search and disagreements were resolved by consensus with a fifth reviewer.

\section{Biologics, biosimilars and generics}

There are some important differences between biologics, biosimilars and generic drugs. Biologics are large molecules with structural complexity with active drug substance made by or derived from a living organism (2). Biologics are $\mathrm{mAb}$, immunomodulators, therapeutic proteins and growth factor substances derived from living organisms. Using genetic techniques, genes are incorporated into the cells of bacteria and other organisms (6).

Biosimilars are copies of biological medicines, usually with the same indication and recommended at the same dosage. Extrapolation represents the approval of a biosimilar for use in an indication held by the reference biologic, not directly studied in a comparative clinical trial with the biosimilar (7). Extrapolation bridges all data collected from one indication of the biosimilar to all the indications originally approved for the reference medicine, it extends the efficacy and safety data from an indication for which the biosimilar had been tested to other indications for which the originator is approved (8).

Biosimilars are alternatives of originator biologics, but not generic versions of originator. Biosimilars are highly similar copies of biological medicines, equally effective and safe (2). The biosimilar product is highly similar to the reference product and minor differences in its clinically inactive components are accepted, but without any clinically meaningful differences (9). Biologics cannot be exactly replicated, as they are heterogeneous, complex molecules.

There are important differences between biosimilars and generic drugs; the active ingredients of generics are the same as those of brand name drugs and the manufacturer must demonstrate that the generic is bioequivalent to the brand name drug, while manufacturers for biosimilars must demonstrate that the biosimilar is highly similar to the reference product, except for minor differences in clinically inactive components and that the differences are not meaningful in terms of safety, purity, and potency (10). EMA defines a generic medicine as a drug that is the same as a medicine which has already been authorized (the 'reference medicine'), which contains the same active substances and which are indicated at the same doses for the same diseases (11). Generic drugs have small molecular chemical structure and they are exact copies of the original non-biologic drugs (12), they are chemically identical, in contrast with biosimilars, which are drugs similar to the reference product in terms of structure, function, and biologic activity (13).

Unlike generic drugs, which must undergo only bioequivalence trials, biosimilars must undergo comparative pharmacokinetic and pharmacodynamic clinical studies (phase I trials) and comparative efficacy trials (phase III trials). Comparability studies showing that the biosimilar has comparable quality, safety, and efficacy are required (14). Clinical trials that biosimilars must undergo include assessments of pharmacodynamics, pharmacokinetics and immunogenicity, and clinical trials should address one or more indications licensed for the originator (15).

In 2005, EMA issued the first guidelines for approval of biosimilars (6). Regulatory requirements for approval of biosimilars are generally similar across EMA, Health Canada, WHO and FDA. These established regulatory pathways include comparative assessments involving analytical,non-clinical, and clinical studies. Regulations require head-to-head comparative studies for structural characterization, functional in vitro assays, pharmacokinetic and pharmacodynamic evaluations, safety, efficacy and immunogenicity assessments (13).

Before receiving marketing authorization, the patent of the originator should have expired. Biosimilar versions of biologics undergo clinical trials that ensures the comparability of the biosimilar to the originator. A biosimilar, generally, may obtain license for fewer than all indications for which the reference product is licensed (9).

\section{Manufacturing biosimilars}

Every biosimilar on the market begins its development after analyzing many lots of the reference product. After defining the 'fingerprint' of the originator, similarities criteria are established (16). The next step is to select the cell line in which the protein will be expressed (mammalian cells, bacterial or yeast cells); the DNA is introduced into cells and once optimal sequences are obtained and production cell line is identified, the cell culture develops in order to produce the target protein. The next step is to undergo a purification process that assures the similarity, and a formulation process that assures the stability of the drug. Protein purification removes impurities that might be immunogenic. Biosimilars are usually kept at $2-8^{\circ} \mathrm{C}$ in order to maintain their efficacy and safety, but exceptions may apply (17).

If a company wants to copy a biologic medicine, it must develop its own manufacturing process because detailed information about how biologics are made is not published. Biologic drugs are complex molecules produced by living cells through a difficult manufacturing process, which involves simultaneously controlling dozens of input parameters such as temperature, flow rates or $\mathrm{pH}$, while performing quality control checks in each phase $(16,18)$.

When manufacturing biosimilars, the variability should be maximally reduced. The key characteristics of these molecules, known as critical quality attributes (CQAs), can vary based on post-translational modifications (PTM; means further differentiation a protein undergoes after translation) that occur in the cellular environment or during the manufacturing process. The extent of the variation in each of the CQAs must be characterized for the originator molecule and systematically matched as closely as possible by the biosimilar developer to ensure biosimilarity (16). Common PTMs are glycosylation, oxidation, phosphorylation, sulphation, lipidation, disulphide bond formation and deamidation. Variations of $\mathrm{pH}$ or growth rate can affect PTM with functional consequences. Even simple 
Table I. Biosimilar medicines used in dermatology approved by European Medicines Agency (33).

Active substance

Adalimumab (monoclonal antibody)

Etanerecept (fusion protein)

Infliximab (monoclonal antibody)
Biosimilars

Date of authorization
Amgevita and Solymbic (ABP 501)

Cyltezo (BI 695501)

Imraldi (SB5)

Benepali (SB4)

Erelzi (GP2015)

Flixabi (SB2)

Inflectra and Remsima (CT-P13)
$22 / 03 / 2017$

$10 / 11 / 2017$

24/08/2017

$14 / 01 / 2016$

23/06/2017

$26 / 05 / 2016$

$10 / 09 / 2013$ changes modify the structure of the drug and it may cause a drug to malfunction via aggregation or immunogenicity (19).

Changes in product quality that may affect safety and efficacy are due to three types of variability: normal batch-to-batch variability, manufacturing drift or intentional changes made by manufacturers. When manufacturers adopt planned changes to improve biosimilar drugs, comparability exercises, including new non-clinical, clinical, or pharmacovigilance studies, are conducted in order to to ensure that safety and efficacy of the product is the same (20).

Patients must be tested for anti-biosimilar antibodies during pre-authorization clinical trials of the drug. Immunogenicity must be included in the risk management plan and it is important for post-authorization pharmacovigilance. EMA published specific guidance on immunogenicity testing of biologics (21).

Because biologics can never be replicated exactly, normal batch-to-batch variability is expected (22). Biologics manufacturing process drifts over time, additional variation may occur due to other unknown variables and it can induce gradual changes or a sudden shift in a quality attribute (23).

The final drug may be affected if there are modifications in manufacturing steps: cloning, host cells, cell culture, purification, formulation or packaging (6).

Immunogenicity is important when speaking of safety of biosimilars. The clinical manifestations of antibodies may include loss of efficacy, neutralization of the natural counterpart and general immune system effects (24).

\section{Biosimilar medicines used in dermatology approved by EMA}

Biological medicines may be small molecule mimetics, recombinant proteins, mAbs or fusion proteins (5).

mAbs are antibodies with a defined specificity derived from cloned cells or organisms. They can be obtained from immortalized B lymphocytes that are cloned and expanded as continuous cell lines (murine and human monoclonal antibodies) or from rDNA-engineered mammalian or bacterial cell lines (engineered $\mathrm{mAb}$ ) (25). Tumor necrosis factors are a family of cytokines involved in systemic inflammation, which includes TNFs and lymphotoxins. TNF- $\alpha$-blocking drugs are efficient in the treatment of chronic inflammatory disorders as they reduce rapidly the number of cells present at the inflammation area, but also, as a result of suppressing the immune system, TNF- $\alpha$ inhibitors have been associated with serious infections (26). Other severe adverse events of biologics include cancers, neurological conditions, worsening the heart failure $(27,28)$.

Now, there are 9 biosimilar medicines approved by EMA for plaque psoriasis and hidradenitis suppurativa: Amgevita, Solymbic, Cyltezo, Imraldi, Benepali, Erelzi, Flixabi, Inflectra and Remsima, and their number is increasing (Table I). Psoriasis and hidradenitis suppurativa are chronic inflammatory skin disorders with a major negative impact on quality of life $(29,30)$. In psoriasis, clinical examination reveals erythemato-squamous papules and plaques, mainly located on the arms, elbows, knees, scalp and trunk (31). Lesions are caused by accelerated proliferation and abnormal differentiation of epidermal keratinocytes as a reaction to the activation of the immune system $(32,33)$. Hidradenitis suppurativa is a dermatological disease characterized by painful abscesses, nodules and scarring, predominantly in axillary and groin regions (34). When systemic non-biologic drugs (e.g., methotrexate, cyclosporine, acitretin for psoriasis and antibiotics or retinoids for hidradenitis suppurativa) are ineffective, biologics are the next therapeutic step $(35,36)$.

Many companies are developing candidates for biosimilars and information on clinical trials is recorded on the websites: clinicaltrials.gov from United States and clinicaltrialsregister. eu from Europe (37).

TNF- $\alpha$-blocking biosimilars used in dermatology are infliximab (mAb), adalimumab (mAb) and etanercept (fusion protein). Ustekinumab is a mAb effective in the treatment of psoriasis but with no biosimilars approved for patients with dermatological diseases (38).

Etanercept (Benepali and Erelzi are biosimilars approved by EMA) is p75 receptor fusion protein of human TNF with an $\mathrm{Fc}$ fragment produced in a system of mammal expression in Chinese hamster ovary cells (26). It is a chimeric protein dimer engineered by fusing the extracellular ligand binding domain of TNFR2/p75 to the Fc domain of human IgG1 (the hinge region and the $\mathrm{C}_{\mathrm{H}} 2$ and $\mathrm{C}_{\mathrm{H}} 3$ regions) (39). Etanercept has the stability of an antibody and the specificity of a receptor (40). It acts as a competitive inhibitor of TNF and prevents it from binding to its cell surface receptors (39). Etanercept, unlike the other anti-TNF agents, neutralizes the biological activity of both TNF- $\alpha$ and lymphotoxin- $\alpha$.

Adalimumab was the first fully human $\mathrm{mAb}$ approved by FDA in 2002 (37,41). It is a mAb with human-derived heavy 
and light chain variable regions, and human IgG1:k constant regions, which can bind to the soluble and transmembrane forms of TNF- $\alpha$ (26). Amgevita, Cyltezo and Imraldi are biosimilars approved for the treatment of plaque psoriasis and hidradenitis suppurativa.

Infliximab is a human-murine chimeric mAb with a constant human region $(\mathrm{Fc})$ and a variable mouse region $(\mathrm{Fv})$ that presents high specificity for TNF- $\alpha$ in soluble and transmembrane forms, but not for lymphotoxin- $\alpha$ (27). The first biosimilars of the mAb infliximab were approved in 2013 by EMA under the brand names of Remsima and Inflectra (42).

\section{The future pathway ahead}

Novel biologics act by novel targets, technology and mechanisms of action compared to previously approved biologics. Next-generation biologics, called 'biobetters', have the same target or mechanism of action as previously approved biologics, but they include structural changes, bifunctional targeting and an improved formulation that may optimize the clinical profile of the patient. Longer half-life allowing less frequent dosing, more potency and less toxicity, are innovations sustained by the new reality of biosimilar competition. As know, competition leads to innovation.

\section{Conclusions}

Biologic drugs are unique because, unlike usual drugs, they are not chemically synthesized. The debate over the future of the biosimilars is far from being finished. The explosive development of biological therapy and the emergence of biosimilars, as revolutionary tools against the most serious and provocative diseases, represent a significant success in the effort to provide advanced healthcare to patients all over the world.

\section{Acknowledgements}

Not applicable.

\section{Funding}

No funding was received.

\section{Availability of data and materials}

All data generated or analyzed during this study are included in this published article.

\section{Authors' contributions}

MMC contributed to the design of the study and revised it critically for important intellectual content. CMC, TT, SB and TC were responsible for the acquisition of the data by screening the studies identified on Pubmed and disagreements were resolved by consensus with a fifth reviewer, AD. CMC, TT and SB revised the study critically for important intellectual content. TC, AD and IEN were involved in editing and drafting the study. AD made substantial contributions to analysis of data and she has been involved in drafting the manuscript. IEN analyzed and interpreted the data. MJ contributed to the conception of the study, she revised the language and contributed to drafting the study. All authors agreed to be accountable for all aspects of the study in ensuring that questions related to the accuracy or integrity of any part of the study are appropriately investigated and resolved. All authors read and approved the final manuscript.

\section{Ethics approval and consent to participate}

Not applicable.

\section{Patient consent for publication}

Not applicable.

\section{Competing interests}

The authors declare that they have no competing interests.

\section{References}

1. Moorkens E, Vulto AG, Huys I, Dylst P, Godman B, Keuerleber S, Claus B, Dimitrova M, Petrova G, Sović-Brkičić L, et al: Policies for biosimilar uptake in Europe: An overview. PLoS One 12: e0190147, 2017.

2. Farhat F, Torres A, Park W, de Lima Lopes G, Mudad R, Ikpeazu C and Abi Aad S: The concept of biosimilars: From characterization to evolution - A narrative review. Oncologist 22: 1-7, 2017.

3. Ratiu MP, Purcarea I, Popa F, Purcarea VL, Purcarea TV, Lupuleasa D and Boda D: Escaping the economic turn down through performing employees, creative leaders and growth driver capabilities in the Romanian pharmaceutical industry. Farmacia 59: 119-130, 2011.

4. European Medicines Agency: Glossary. http://www.ema. europa.eu/ema/index.jsp?curl=pages/document_library/landing/ glossary.jsp\&mid=\&startLetter=A. Accessed March 10, 2018.

5. Purcell RT and Lockey RF: Immunologic responses to therapeutic biologic agents. J Investig Allergol Clin Immunol 18: 335-342, 2008.

6. Ahmed I, Kaspar B and Sharma U: Biosimilars: Impact of biologic product life cycle and European experience on the regulatory trajectory in the United States. Clin Ther 34: 400-419, 2012.

7. Tesser JR, Furst DE and Jacobs I: Biosimilars and the extrapolation of indications for inflammatory conditions. Biologics 11: 5-11, 2017.

8. National Health Service: What is a Biosimilar Medicine? https:// www.england.nhs.uk/wp-content/uploads/2015/09 biosimilar-guide. pdf. Accessed June 10, 2018.

9. Food and Drug Administration: Biologics Price Competition and Innovation Act of 2009; Meetings on User Fee Program for Biosimilar and Interchangeable Biological Product Applications; Request for Notification of Stakeholder Intention To Participate. https://www.federalregister.gov/documents/2010/12/08/2010-30713/ biologics-price-competition-and-innovation-act-of-2009-meetings-onuser-fee-program-for-biosimilar. Accessed June 10, 2018.

10. US Food and Drug Administration: Biosimilar and Interchangeable Products. https://www.fda.gov/Drugs/DevelopmentApprovalProcess/ HowDrugsareDevelopedandApproved/ApprovalApplications/ TherapeuticBiologicApplications/Biosimilars/ucm580419.htm. Accessed June 10,2018.

11. European Medicines Agency: Questions and answers on generic medicines. http://www.ema.europa.eu/docs/en_GB/document_library/ Medicine_QA/2009/11/WC500012382.pdf. Accessed June 10, 2018.

12. Eleryan MG, Akhiyat S, Rengifo-Pardo M and Ehrlich A: Biosimilars: Potential implications for clinicians. Clin Cosmet Investig Dermatol 9: 135-142, 2016.

13. MyslerE, Pineda C, Horiuchi T, Singh E, Mahgoub E, Coindreau J and Jacobs I: Clinical and regulatory perspectives on biosimilar therapies and intended copies of biologics in rheumatology. Rheumatol Int 36: 613-625, 2016.

14. Mielke J, Jilma B, Koenig F and Jones B: Clinical trials for authorized biosimilars in the European Union: A systematic review. Br J Clin Pharmacol 82: 1444-1457, 2016. 
15. Ventola CL: Biosimilars part 1: Proposed regulatory criteria for FDA approval. P T 38: 270-287, 2013

16. Vulto AG and Jaquez OA: The process defines the product: what really matters in biosimilar design and production? Rheumatology 56: iv14-iv29, 2017.

17. Crommelin DJ, Bissig M, Gouveia W and Tredree R: Storage and handling of biopharmaceuticals: Problems and solutions: A workshop discussion. Eur J Hosp Pharm Sci Pract 8: 89-93, 2003.

18. Shimasaki C (ed): Biotechnology Entrepreneurship: Starting, Managing, and Leading Biotech Companies. 1st Edition. Academic Press, Orlando, FL, p383, 2014.

19. Berkowitz SA, Engen JR, Mazzeo JR and Jones GB: Analytical tools for characterizing biopharmaceuticals and the implications for biosimilars. Nat Rev Drug Discov 11: 527-540, 2012.

20. European Medicines Agency: Guideline on comparability of biotechnology-derived medicinal products after a change in the manufacturing process. http://www.ema.europa.eu/docs/ en GB/document library/Scientific guideline/2009/09/ WC̄500003935.pdf. Accessed March 5, 2018.

21. European Medicines Agency: Guideline on Immunogenicity Assessment of Biotechnology - Derived Therapeutic Proteins https://www.ema.europa.eu/documents/scientific-guideline/ guideline-immunogenicity-assessment-biotechnology-derivedtherapeutic-proteins-first-version_en.pdf. Accessed December 13 2007.

22. Patel PK, King CR and Feldman SR: Biologics and biosimilars. J Dermatolog Treat 26: 299-302, 2015.

23. Ramanan S and Grampp G: Drift, evolution, and divergence in biologics and biosimilars manufacturing. BioDrugs 28: 363-372, 2014.

24. Schellekens H: Factors influencing the immunogenicity of therapeutic proteins. Nephrol Dial Transplant 20: vi3-vi9, 2005.

25. European Medicines Agency: Production and Quality Control of Monoclonal Antibodies. http://www.ema.europa.eu/docs/en_GB/ document_library/Scientific_guideline/2009/09/WC500003444. pdf. Accessed March 5, 2018.

26. Silva LC, Ortigosa LC and Benard G: Anti-TNF- $\alpha$ agents in the treatment of immune-mediated inflammatory diseases: Mechanisms of action and pitfalls. Immunotherapy 2: 817-833, 2010.

27. Tantu M, Belu E, Bobescu E, Armean SM, Armean P, Constantin MM and Dominaru CD: Role of angiotensin converting enzyme (ACE) inhibitors in hypertension and cardiovascular protection management. Farmacia 62: 443-451, 2014.

28. Gheunca-Solovastru L, Vata D, Statescu L, Constantin MM and Andrese E: Skin cancer between myth and reality, yet ethically constrained. Rev Rom Bioet 12: 47-52, 2014.

29. Batani A, Brănisteanu DE, Ilie MA, Boda D, Ianosi S, Ianosi G and Caruntu C: Assessment of dermal papillary and microvascular parameters in psoriasis vulgaris using in vivo reflectance confocal microscopy. Exp Ther Med 15: 1241-1246, 2018.
30. Căruntu C, Boda D, Căruntu A, Rotaru M, Baderca F and Zurac S: In vivo imaging techniques for psoriatic lesions. Rom J Morphol Embryol 55: 1191-1196, 2014.

31. Caruntu C, Boda D, Dumitrascu G, Constantin C and Neagu M: Proteomics focusing on immune markers in psoriatic arthritis. Biomarkers Med 9: 513-528, 2015.

32. Negrei C, Arsene AL, Toderescu CD, Boda D and Ilie M: Acitretin treatment in psoriasis may influence the cell membrane fluidity. Farmacia 60: 767-771, 2012.

33. Negrei C, Caruntu C, Ginghina O, Dragomiroiu G, Toderescu CD and Boda D: Qualitative and quantitative determination of methotrexate polyglutamates in erythrocytes by high performance liquid chromatography. Rev Chim 66: 607-610, 2015.

34. Ryan C, Sobell JM, Leonardi CL, Lynde CW, Karunaratne M, Valdecantos WC and Hendrickson BA: Safety of adalimumab dosed every week and every other week: Focus on patients with hidradenitis suppurativa or psoriasis. Am J Clin Dermatol 19: 437-447, 2018.

35. Negrei C, Ginghina O, Caruntu C, Dragomiroiu GB, Jinescu G and Boda D: Investigation relevance of methotrexate polyglutamates in biological systems by high performance liquid chromatography. Rev Chim 66: 766-768, 2015.

36. Boda D, Negrei C, Nicolescu F and Balalau C: Assessment of some oxidative stress parameters in methotrexate treated psoriasis patients. Farmacia 62: 704-710, 2014.

37. Kaushik VV: Review of biosimilars of Adalimumab. J Assoc Physicians India 65: 15-21, 2017

38. Olteanu R, Constantin MM,Zota A, Dorobantu DM, Constantin T, Serban ED, Bălănescu P, Mihele D and Gheucă Solovăstru L: Original clinical experience and approach to treatment study with interleukine 12/23 inhibitor in moderate-to-severe psoriasis patients. Farmacia 64: 918-921, 2016.

39. Wadhwa M, Bird C, Dilger P, Rigsby P, Jia H and Gross MEB; participants of the study: Establishment of the first WHO International Standard for etanercept, a TNF receptor II Fc fusion protein: Report of an international collaborative study. J Immunol Methods 447: 14-22, 2017.

40. Azevedo VF, Galli N, Kleinfelder A, D'Ippolito J and Urbano PCM: Etanercept biosimilars. Rheumatol Int 35 197-209, 2015.

41. Burness CB and McKeage K: Adalimumab: A review in chronic plaque psoriasis. Drugs 75: 2119-2130, 2015.

42. Olteanu R, Zota A and Constantin M: Biosimilars: An update on clinical trials (review of published and ongoing studies). Acta Dermatovenerol Croat 25: 57-66, 2017. 